\title{
13
}

\section{Conclusion: Towards Rights-Based Child Protection Work}

\section{Elisabeth Backe-Hansen and Asgeir Falch-Eriksen}

\section{Introduction}

The purpose of this book has been to critically explore what child protection policy and professional practice entail if they claim to abide by a human rights standard in order to be justified. To achieve this aim, contributions were commissioned that addressed the question of rightsbased, professional child protection work at three levels: the systems level, the policy level and through examples from child protection practices.

In various ways, the authors have responded to the call for critical exploration, which altogether paints a picture of possibilities as well as challenges if rights-based child protection work is to be implemented successfully. One of the strengths of the book is the varied professional backgrounds of the contributors, which have enabled pertinent issues to be addressed from the point of view of the law, political science,

E. Backe-Hansen $(\bowtie) \bullet$ A. Falch-Eriksen

Norwegian Social Research, Oslo Metropolitan University, Oslo, Norway e-mail: ebha@oslomet.no; asgeirer@oslomet.no; asgeir.falch-eriksen@nova. hioa.no 
psychology, social work and sociology. This has both added important richness to the arguments presented throughout, but also insights into the importance of building bridges between academic fields of interest in order to give birth to more accurate and needed research for professional practice and policy development.

Another strength of the book is the choice of empirical examples from a series of countries. One chapter draws on data from 14 countries, while the other chapters utilize examples from Denmark, England, Finland and Norway. All examples were selected analytically because we think readers from any country claiming to enforce the Convention on the Rights of the Child (CRC) will find them both relevant and useful. Each chapter thereby seeks to be relevant to Child Protection Services (CPS) across borders.

In the rest of the chapter, we sum up the most important conclusions and draw out implications for practical child protection work.

\section{The Systems Level}

Chapters 2, 3, 4 and 5 addressed several overarching themes and principles. To be able to explore and critically discuss rights-based professional work within child protection, we need to immerse ourselves in children's rights, and how these rights ought to be understood as human rights. Since the book concerns child protection, Article 19 in the CRC, that is the right to protection, was a logical point of departure (Sandberg, Chap. 2 ). In addition comes theorizing about rights-based child protection work (Falch-Eriksen, Chap. 3), comparative analyses of legislation concerning the principle of the best interests of the child (Skivenes and Sørsdal, Chap. 4), and how to achieve rights-based child protection work through reorganizing the system (Munro and Turnell, Chap. 5).

In some settings it is pedagogical to divide children's rights into categories, like participation rights (Article 12), protection rights (Article 19) and provision rights (Article 27). One essential reminder form Sandberg's discussion of Article 19 is that children's rights are indivisible. One cannot pick and choose rights, but must see all rights under the umbrella of a human rights standard, as a perspective and in relation to each other. 
Thus, child protection workers need to know not only the CRC from a formal and semantic point of view, but also what the CRC implies as a human rights standard set to govern 'all actions concerning children' (cf. CRC Art. 3). Hence, rights are not only viewed in relation to formal decisions regarding a child and his or her parents, but must also become an integral part of the investigation and assessment process.

Article 19 states that children have the right to be protected from all kinds of maltreatment, which can also justify out-of-home placement if absolutely necessary. A challenge resulting from the formulation in Article 19 and the specifications in General Comment (GC) No. 13 is that the definition of maltreatment is extremely wide. In a sense, anything a child is exposed to has the potential to be classified as maltreatment. Thus, practitioners must depend on national legislation for definitions of maltreatment that justify intervention from CPS. As Skivenes and Sørsdal (Chap. 4) point out, however, national legislation varies considerably when it comes to describing relevant situations and the scope of discretion delegated to professionals. Thus, practitioners need to be familiar with national legislation and regulations and the position of professional discretion in decision-making, and use this knowledge as an important basis for their decision-making.

Both Falch-Eriksen (Chap. 3) and Skivenes and Sørsdal (Chap. 4) remind us that the principle of the best interests of the child is indeterminate. Making a decision which is really and truly in a child's best interest thus necessitates taking into account the individual child's situation, wishes and prospects. But this does not necessarily mean that these are the only considerations. As Skivenes and Sørsdal argue, sufficient general knowledge about what children need exists for us to use this as a factual basis for decisions as well. However, as Falch-Eriksen underlines, if a decision does not approximate the principle of the child's best interests in decision-making, but relies too heavily on general knowledge, the practice departs from the human rights ethos of the CRC. Furthermore, as Christiansen and Hollekim argue (Chap. 10), general views about children's needs become problematic if they become too ideological and lose sight of the large variation that exists in conjunction with the commonalities. Not in the least, class, culture and gender influence our general views of children's needs. Thus, child protection workers need to address 
indeterminacy in an adequate manner, through combining individualized assessments with factual knowledge, while at the same time taking into account that generalized knowledge might be flawed or unfit for a child.

This conclusion resonates with Munro and Turnell (Chap. 5), who argue that a truly rights-based approach presupposes decision-making designs and systems that open up in the direction of a critical, reflective and collaborative practice at the street level. This shift has to be endorsed by the administrative level if it is to succeed, which is a well-known result from other research on the implementation of systems changes. Munro and Turnell also give an example of an approach that can accommodate a human rights-standard in decision-making (Signs of Safety). Signs of Safety is designed to ensure children's participation throughout a child protection case process, involving the parents as well. Implementing this method depends on the kind of practice they endorse. Thus, the child protection system needs to endorse critical and reflective practices if a rights-based professional practice is to have any chance of success.

\section{The Policy Level}

Chapters 6, 7, 8 and 9 concern rights-based child protection work at the policy level or what professional child protection practice can learn through researching various policies. First, in Chap. 6, Pösö addresses collective participation by groups of child welfare youth. Hestbæk shows how there is a need for improvement in rights-based work in CPS, particularly in residential care (Chap. 7), while Gording-Stang (Chap. 8) discusses how protection rights can be enforced in emergency placements. Finally, we are reminded about the need to also keep provision rights at the forefront when aiming to protect children from maltreatment as well as realizing other rights (Heggem Kojan and Clifford, Chap. 9).

Experts by experience as a form of collective participation have gained a large impact during the last decade or so. As Pösö (Chap. 6) argues, the impact is perhaps greater on policymakers than on street-level workers. Experts by experience share their biographies in ways that resonate with today's individualized society, and with our wish to make a difference for a group of children and young people who have had a bad deal by society 
and their parents. One reason why street-level workers may be less influenced is that experts by experience do not address systems and structures (nor can they be expected to do so). Thus, child protection workers need to listen carefully to what experts by experience can tell them, but at the same time they need to relate this knowledge to the system of which they are a part in order to be able to use the knowledge professionally.

While Pösö discusses collective participation as a matter of right, Anne-Dorthe Hestbæk (Chap. 7) uses information collected from individuals through a survey study among children and young people in foster and residential care. This creates different but no less important knowledge. It rather illustrates the variety of areas where rights-based practice needs to be developed. Hestbæk found significant differences between the well-being of those in foster care and those in residential care, with far greater challenges associated with the latter. What she shows as well is that it is fairly easy to 'translate' often-used questions about safety and well-being to children's rights terms. This gives new insights about possibilities and challenges when it comes to developing rightsbased professional practices in out-of-home care, particularly residential care. Thus, child protection workers need to use knowledge about children's rights and national legislation and regulations as a basis for framing residential care in ways that promote rights-based practices.

The use of emergency out-of-home placements challenges decisionmakers both in CPS and the courts, as Elisabeth Gording-Stang (Chap. 8) shows in her analysis of decisions that were made in ten court cases from Norway. Provisions for such placements exist across jurisdictions, but they are often contested, and sometimes accepted for assessment by the European Court of Human Rights. There is a need for provisions enabling CPS to overrule other considerations when a child's need for protection through out-of-home placement is sufficiently paramount. However, the threshold is high, maybe too high, and it is important for CPS to assess carefully whether a case should rather be accorded full judicial treatment. Thus, child protection workers again need to know both the CRC and national legislation and regulations, besides comparable decisions already made, as a decision aid in concrete cases.

Bente Heggem Kojan and Graham Clifford (Chap. 9) use as their point of departure the fact that social and economic marginalization is 
widespread among families in contact with CPS. As well, there is across countries a well-known correlation between being marginalized and coming into contact with CPS. This makes it important to ensure that children's provisions rights, or welfare rights, are enforced by CPS or adjacent social or welfare services targeting children and families. The authors point out that protecting children and promoting their welfare mean that professionals need to reframe their approach. Child protection workers need to pay attention to the environments and contexts in which children live; like families, school and leisure time.

Kojan and Clifford use children's right to education (CRC Article 28) as a practical example, since poor educational attainment is a risk factor for later marginalization in today's knowledge-based societies. As they point out, we cannot expect all parents in contact with CPS to be able to help their children sufficiently by themselves. Parents often lack resources to do so, have often themselves had trouble at school and ended up with poor educational attainment, besides having trouble coping with their daily lives. Thus, child protection workers need to engage themselves in children and young people's schooling, and the authors suggest four areas. First, child protection workers need knowledge about the school situation of all children they are responsible for. Second, they need to be proactive in their contact with the children's school, ensuring ongoing and updated knowledge. Third, helping children living at home with their school work and situation needs to be part of what CPS prioritizes for children receiving in-home preventive services. Finally, but not least importantly, child protection workers need to know the children they meet, what abilities and cognitive potential they have, something which is too often undervalued by social workers and others alike.

\section{Three Examples from Child Protection Practice}

The final three chapters in the book delved into important areas of child protection practice in greater detail. In accordance with CRC Article 19, in-house preventive work is prioritized whereas out-of-home placements are to be avoided if possible. Øivin Christiansen and Ragnhild Hollekim 
(Chap. 10) discuss some challenges that may arise if this kind of practice, which presupposes collaboration with both parents and children, at the same time can succeed in being rights-based on the part of the children. In her chapter, Cecilie Basberg Neumann (Chap. 11) analyses the provision of care in a residential unit for severely troubled children, and how it is possible to ensure that children's protection and participation rights are met through the use of bodily contact. Finally, Elisabeth BackeHansen (Chap. 12) addresses participation rights for children in foster families when foster children and children already in the foster home do not have the same standing.

As Christiansen and Hollekim show, there will often be many reasons why in-home preventive services are initiated. Child maltreatment need not play a very prominent part, as parents' mental health issues, drug abuse or more general family problems often dominate. And in many cases, there are multiple problems to be addressed, including poor educational attainment on the part of the child, or even serious behavioural problems. However, whatever the reason for initiating services, they are supposed to realize children's rights, that is help improve the child's situation at home.

Christiansen and Hollekim discuss two important challenges in this respect. The first is how to realize children's rights when the parents do not consent. This may lead to children not getting sufficient help, which may again necessitate more intrusive interventions at a later stage, or to parents consenting anyway because they feel coerced to do so for fear of the consequences if they refuse. The second challenge is related to today's trend to target parents with guidance and advice, and whether this is actually sufficient in the way stated in CRC Article 19. Kojan and Clifford (Chap. 9) pointed out that it might seem as if today's choice of interventions do not help those with the most serious problems.

Finally, Christiansen and Hollekim warn against current trends to homogenization of parenthood, a narrowed understanding of the complexity of children and parents' needs, and a marginalization of the child following from the present trend to educate and supervise parents. Thus, child protection workers need to be aware of the delicate balance between motivating parents and children and recognizing their right not to consent. It is also necessary to keep in mind the complexity of the lives 
children and parents in contact with CPS lead, and remember the indivisibility and indeterminacy following from rights-based work.

Cecilie Neumann (Chap. 11) asked what care workers do when they provide care to young children in residential settings, and what good care has to do with realization of the principle of the child's best interests and children's right to participation. Through fieldwork in one such setting, she came to the conclusion that good care of children was related to care worker's bodily awareness, and a sensitive presence when interacting with and caring for the children. It is important to focus on positive practices involving bodily contact in today's climate of scepticism and fear of abuse in institutions.

Working with children in residential units, child protection workers thus need to pay attention to how the children's need for physical contact or regulation of physical contact is met by the care workers, and how positive interactions also increase the children's ability to participate and be part of life on the unit. The ways this happen will vary with the children's age and what their problems are, but the principles remain the same.

Backe-Hansen (Chap. 12) chose as her point of departure what may happen when a child is placed in a foster home with participatory rights that follow from CRC Article 12.1 and 12.2, in a formal way, in contrast to how participation is an integrated part of daily life in the family. CPS also tend not to involve children already in the foster family when a child is to be placed within that family, but concentrate on the latter. In contrast, foster families are 'public' families, and foster parents have to accept that they have less authority as foster parents than they have as parents, and have to accept more intrusion and control from outside.

Backe-Hansen argues that these factors create imbalances in foster families, which may lead to less stable placements. Thus, three things are important for child protection workers. First, they need to reduce the imbalance between children in the foster family by involving those already there in the placement process - through informing them, and asking about their views. Second, workers need to accede foster parents sufficient authority to enable the parents to actually act as parents in the daily lives of the family, thus being able to protect them sufficiently as well. Third, it must be remembered that children's participation is 
relational in nature-children always participate in relation to someone, be that parents, foster parents, siblings, friends, other grown-ups and so on.

\section{Conclusion}

The book contains far more discussion, suggestions and insights than it has been possible to sum up in this concluding chapter. It also contributes theoretical insights and developments that need to be studied in depth in the chapters. For this concluding chapter, we aimed to draw out the most important lessons for child protection work at the street level. In other words, what can and should child protection workers do in order to develop rights-based, professional practice? Many answers have been given here.

Open Access This chapter is licensed under the terms of the Creative Commons Attribution 4.0 International License (http://creativecommons.org/licenses/ by/4.0/), which permits use, sharing, adaptation, distribution and reproduction in any medium or format, as long as you give appropriate credit to the original author(s) and the source, provide a link to the Creative Commons license and indicate if changes were made.

The images or other third party material in this chapter are included in the chapter's Creative Commons license, unless indicated otherwise in a credit line to the material. If material is not included in the chapter's Creative Commons license and your intended use is not permitted by statutory regulation or exceeds the permitted use, you will need to obtain permission directly from the copyright holder.

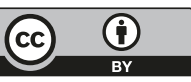

